NASA/CR-1998-208671

$1 N=34$

432204
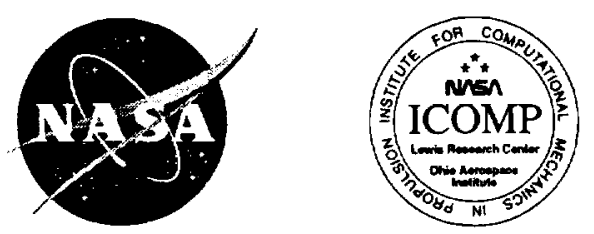

\title{
Evaluation of Boundary Conditions for the Gust-Cascade Problem
}

\section{R. Hixon and S.-H. Shih}

Institute for Computational Mechanics in Propulsion, Cleveland, Ohio

\section{R.R. Mankbadi}

Institute for Computational Mechanics in Propulsion, Cleveland, Ohio, and Cairo University, Cairo, Egypt 
Since its founding, NASA has been dedicated to the advancement of aeronautics and space science. The NASA Scientific and Technical Information (STI) Program Office plays a key part in helping NASA maintain this important role.

The NASA STI Program Office is operated by Langley Research Center, the Lead Center for NASA's scientific and technical information. The NASA STI Program Office provides access to the NASA STI Database, the largest collection of aeronautical and space science STI in the world. The Program Office is also NASA's institutional mechanism for disseminating the results of its research and development activities. These results are published by NASA in the NASA STI Report Series, which includes the following report types:

- TECHNICAL PUBLICATION. Reports of completed research or a major significant phase of research that present the results of NASA programs and include extensive data or theoretical analysis. Includes compilations of significant scientific and technical data and information deemed to be of continuing reference value. NASA's counterpart of peerreviewed formal professional papers but has less stringent limitations on manuscript length and extent of graphic presentations.

- TECHNICAL MEMORANDUM. Scientific and technical findings that are preliminary or of specialized interest, e.g., quick release reports, working papers, and bibliographies that contain minimal annotation. Does not contain extensive analysis.

- CONTRACTOR REPORT. Scientific and technical findings by NASA-sponsored contractors and grantees.
- CONFERENCE PUBLICATION. Collected papers from scientific and technical conferences, symposia, seminars, or other meetings sponsored or cosponsored by NASA.

- SPECIAL PUBLICATION. Scientific, technical, or historical information from NASA programs, projects, and missions, often concerned with subjects having substantial public interest.

- TECHNICAL TRANSLATION. Englishlanguage translations of foreign scientific and technical material pertinent to NASA's mission.

Specialized services that complement the STI Program Office's diverse offerings include creating custom thesauri, building customized data bases, organizing and publishing research results ... even providing videos.

For more information about the NASA STI Program Office, see the following:

- Access the NASA STI Program Home Page at http:/lwww.sti.nasa.gov

- E-mail your question via the Internet to help@sti.nasa.gov

- Fax your question to the NASA Access Help Desk at (301) 621-0134

- Telephone the NASA Access Help Desk at (301) 621-0390

- Write to: NASA Access Help Desk NASA Center for AeroSpace Information 7121 Standard Drive Hanover, MD 21076 
NASA/CR-1998-208671
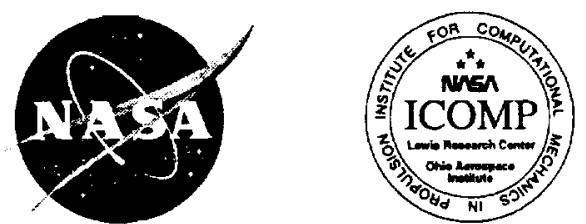

\section{Evaluation of Boundary Conditions for the Gust-Cascade Problem}

R. Hixon and S.-H. Shih

Institute for Computational Mechanics in Propulsion, Cleveland, Ohio

R.R. Mankbadi

Institute for Computational Mechanics in Propulsion, Cleveland, Ohio, and Cairo University, Cairo, Egypt

Prepared under Cooperative Agreement NCC3-531

National Aeronautics and

Space Administration

Lewis Research Center 


\section{Acknowledgments}

This work was carried out under grant NCC3-531 from the NASA Lewis Research Center.

Dr. L.A. Povinelli was the Technical Monitor.

Available from

NASA Center for Aerospace Information

7121 Standard Drive

Hanover, MD 21076

Price Code: A03
National Technical Information Service 5285 Port Royal Road Springfield, VA 22100 


\title{
EVALUATION OF BOUNDARY CONDITIONS FOR THE GUST- Cascade Problem
}

\author{
R. Hixon and S.-H. Shih \\ Institute for Computational Mechanics in Propulsion (ICOMP) \\ NASA Lewis Research Center, Cleveland, $\mathrm{OH} 44135$ \\ R. R. Mankbadi \\ Institute for Computational Mechanics in Propulsion (ICOMP) \\ NASA Lewis Research Center, Cleveland, OH 44135 \\ and \\ Cairo University, Cairo, Egypt
}

\begin{abstract}
Using a high-order accuracy finite-difference time-domain algorithm, the acoustic scattering from a flat-plate cascade is computed. Keeping the grid and time step fixed, the effect of four different boundary conditions on the accuracy and stability of the computed solution is compared.
\end{abstract}

\section{Introduction}

Despite recent efforts to introduce quieter aircraft, it is expected that noise will increase as a barrier to air transportation ${ }^{1-3}$. For high-by-pass jet engines, fan noise becomes comparable to jet noise ${ }^{4}$. With current emphasize placed on jet noise reduction, fan noise could become the dominant noise source in the near future. Fan noise can be classified into three main sources ${ }^{5}$ inlet boundary layer or inflow distortions interacting with the fan; self noise from the fan; and fan wakes interacting with stators or struts. Both tone noise and broadband noise can be generated.

The gust-cascade interaction can be taken as representing the interaction of inflow disturbances with the fan or the interaction of the fan wakes with the stator ${ }^{6,7}$. In the simplest gust-cas- 
cade model the blades are represented as two-dimensional flat plate cascades stacked in the spanwise direction. The inflow distortions or the fan wakes are represented by vortical gusts convected with the mean flow. The interaction of the gust with the blades produces unsteady pressure distribution over the blades' surfaces. If this unsteady surface pressure is coupled to the propagation duct modes inside the nacelle, the radiated inlet and exhaust sound can be obtained. Classical work on the gust cascade problem has relied on approximate analysis and empirical formulation and is reviewed by Huff in Ref. 5 . The two- dimension gust-cascade interaction has been studied by Kaji and Okazaki ${ }^{8}$. Three-dimensional effects are considered by Namba who pointed out that 3-D effects become less important at high acoustic-response frequencies ${ }^{9}$. Effects of loading and nonuniform transonic flow are given by Atassi et al. ${ }^{10}$. Effects of camber, thickness and stagger angles are given in Lorence and Hall ${ }^{11}$.

In the present decade considerable progress in the relatively new science of Computational Aero-Acoustics (CAA) has been achieved. In CAA, the unsteady governing equations are discretized and solved for time-dependent flow variables, which includes the mean flow and the flow or acoustic disturbances. High-order schemes are required for discretization to reduce dissipation and dispersion errors. But high-order schemes support the formation of spurious modes at the boundaries of the computational domain. Careful attention for unsteady boundary treatment is needed to produce the physically correct disturbance field.

Considerable progress has been made in applying CAA to jet noise (see review articles by Mankbadi ${ }^{12}$ and $\operatorname{Tam}^{13}$ ). Application of CAA to fan noise is still limited, and it is required to demonstrate first the ability of CAA to accurately predict simple models of fan noise elements. To achieve this purpose the gust-cascade model was considered as benchmark problem in second workshop on bench mark problems for $\mathrm{CAA}^{14}$. The amplitude of the gust was taken to be small; 
thus, either the linearized or the full Euler equations can be used and comparison with analytical theories can be made. The objective was to demonstrate what CAA algorithms can offer as eventual substitute for simpler source models. Several algorithms were used to compute this problem $^{15-17}$, and the results were compared to a solution from Hall ${ }^{18}$. The computed results, however, varied considerably from Hall's solution and from each other.

It is suspected that the unsteady boundary treatment could be responsible for the discrepancy between the above simulations of the same gust-cascade problem. This might be particularly true for the time-domain simulations, where no exact boundary treatment exists. This issue is addressed in this paper. We show that the inflow and outflow treatment has considerable influence on the solution. Some boundary treatments are shown to produce satisfactory agreement with theory given a longer computational domain.

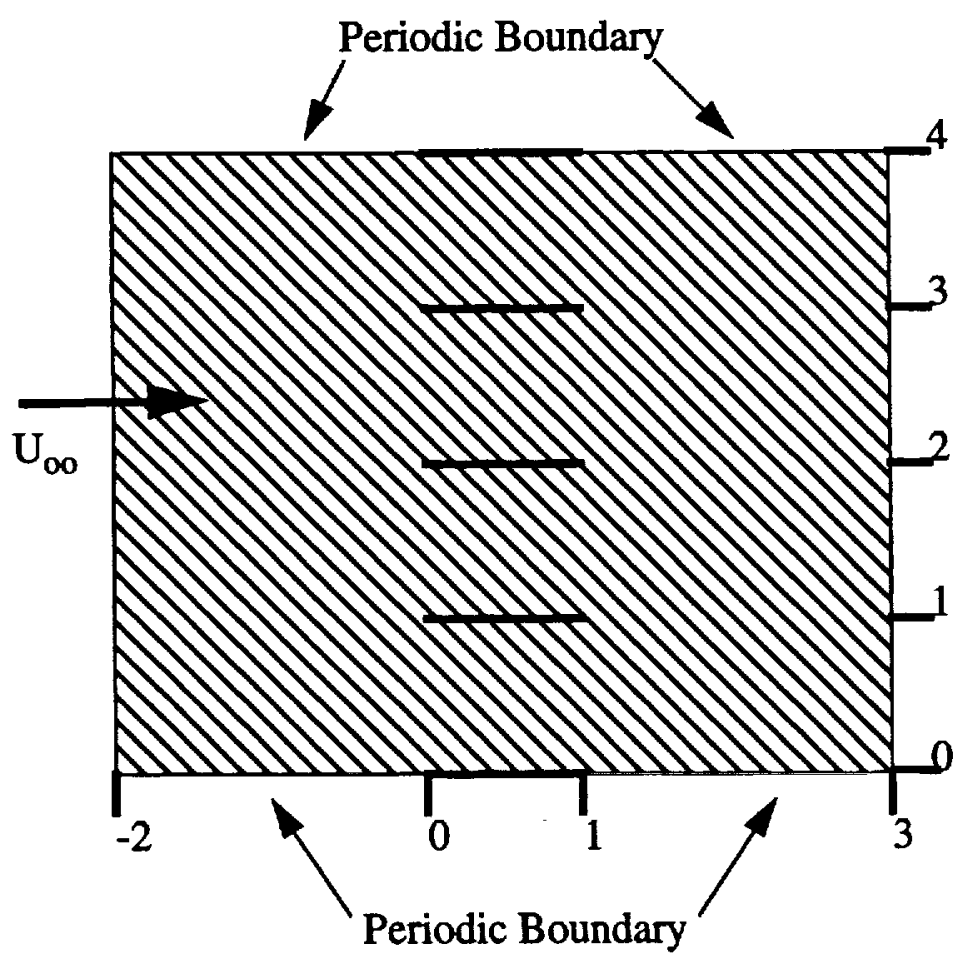

Figure 1: Turbomachinery Noise Benchmark Problem 


\section{Problem Statement}

This benchmark problem consists of four flat-plate airfoils in an unstaggered cascade, shown in Fig. 1. In this problem, a periodic vortical gust is convected in a uniform mean flow, impinging on the flat-plate cascade and radiating noise upstream and downstream. At the inflow boundary, the mean flow and vortical gusts are defined as:

$$
\begin{gathered}
\frac{U_{\infty}}{c_{\infty}}=0.5 \\
u_{g u s t}=-\frac{A \beta}{\alpha} \cos (\alpha x+\beta y-\omega t) \\
v_{g u s t}=A \cos (\alpha x+\beta y-\omega t)
\end{gathered}
$$

where

$$
\begin{gathered}
A=0.01 \\
\alpha=\beta=\omega=\frac{5 \pi}{2}
\end{gathered}
$$

The computational domain is limited to:

$$
\begin{gathered}
-2 \leq x \leq 3 \\
0 \leq y \leq 4
\end{gathered}
$$


This problem is to be solved with either the linearized or the full Euler equations. The output requested is: (1) the real and imaginary component of the pressure jump across the airfoil, and (2) the intensity of the radiated sound $\bar{p}^{2}$ at the inflow and outflow boundaries.

\section{Governing Equations and Numerical Formulation}

The conservative 2-D Euler equations in Cartesian coordinates are given as:

$$
\left\{\begin{array}{c}
\rho \\
\rho u \\
\rho v \\
E
\end{array}\right\}_{t}+\left\{\begin{array}{c}
\rho u \\
\rho u^{2}+p \\
\rho u v \\
u(E+p)
\end{array}\right\}_{x}+\left\{\begin{array}{c}
\rho v \\
\rho u v \\
\rho v^{2}+p \\
v(E+p)
\end{array}\right\}_{y}=0
$$

where

$$
p=(\gamma-1)\left(E-\frac{1}{2} \rho\left(u^{2}+v^{2}\right)\right)
$$

The numerical solver is a high-order accurate finite-difference time-domain scheme. The spatial derivatives are computed using a split sixth-order compact scheme ${ }^{19}$, and the time integration is performed using Hu's 5-6 Low Dispersion and Dissipation Runge-Kutta method ${ }^{20}$. The grid used is a uniform Cartesian grid where $\Delta x=\Delta y=0.02$. Since the vortical gust has a wavelength of 0.8 , this gives 40 points per wavelength, which produces a linear dispersion error of 1.e-9.

For all calculations, the time step used was $\Delta t=0.0125$, which corresponds to a CFL number 
of 1.2 .

\section{Boundary Condition Formulation}

\section{1) Thompson $\mathrm{BC}$}

The Thompson boundary condition ${ }^{21-22}$ uses 1-D characteristic theory to determine the proper boundary condition specification. In the Thompson method, we only consider the effect of the characteristics normal to the boundary; the tangential derivative terms are considered to be a source term. Thus, Eq. (4) becomes:

$$
\left\{\begin{array}{c}
\rho \\
\rho u \\
\rho v \\
E
\end{array}\right\}+\left\{\begin{array}{c}
\rho u \\
\rho u^{2}+p \\
\rho u v \\
u(E+p)
\end{array}\right\}_{x}=\{S\}
$$

The normal flux term is then linearized and decomposed into 1-D characteristics:

$$
\begin{gathered}
\left(c_{1}\right)_{t}+(\bar{u}-\bar{c})\left(p_{x}^{\prime}-\bar{\rho} \bar{c} u_{x}^{\prime}\right)=0 \\
\left(c_{2}\right)_{t}+\bar{u}\left(\bar{c}^{2} \rho_{x}^{\prime}-p_{x}^{\prime}\right)=0 \\
\left(c_{3}\right)_{t}+\bar{u} v_{x}^{\prime}=0 \\
\left(c_{4}\right)_{t}+(\bar{u}+\bar{c})\left(p_{x}^{\prime}+\bar{\rho} \bar{c} u_{x}^{\prime}\right)=0
\end{gathered}
$$

where the overbar terms denote mean quantities. Thus, at the outflow boundary, 


$$
\begin{aligned}
\rho^{\prime} & =\rho-\bar{\rho} \\
u^{\prime} & =u-\bar{u} \\
v^{\prime} & =v-\bar{v} \\
p^{\prime} & =p-\bar{p}
\end{aligned}
$$

However, the incoming vortical gust must be specified at the inflow boundary. To accomplish this,

$$
\begin{gathered}
\rho^{\prime}=\rho-\bar{\rho} \\
u^{\prime}=u-\bar{u}-u_{g u s t} \\
v^{\prime}=v-\bar{v}-v_{g u s t} \\
p^{\prime}=p-\bar{p}
\end{gathered}
$$

These characteristics given in Eq. (7) represent, respectively, the left-running acoustic wave, the entropy wave, the vorticity wave, and the right-running acoustic wave. In Thompson's approach, the direction of travel of the characteristic determines if it is propagating into or out of the domain. The characteristics that are propagating out of the domain are left unchanged; those propagating into the domain are set to zero.

Once the characteristics are determined, the time derivatives of the primitive variables are given as: 


$$
\begin{gathered}
\rho_{t}=\frac{\left(2\left(c_{2}\right)_{t}+\left(c_{1}\right)_{t}+\left(c_{4}\right)_{t}\right)}{2 \bar{c}^{2}} \\
p_{t}=\frac{\left(c_{1}\right)_{t}+\left(c_{4}\right)_{t}}{2} \\
u_{t}=\frac{\left(c_{4}\right)_{t}-\left(c_{1}\right)_{t}}{2 \bar{\rho} \bar{c}} \\
v_{t}=\left(c_{3}\right)_{t}
\end{gathered}
$$

With the primitive variables now known, the time derivative of the conserved variables are calculated as:

$$
\begin{gathered}
(\rho u)_{t}=\bar{\rho} u_{t}+\bar{u} \rho_{t} \\
(\rho v)_{t}=\bar{\rho} v_{t} \\
E_{t}=\frac{1}{2}\left(\bar{u}^{2}\right) \rho_{t}+\frac{p_{t}}{\gamma-1}+\bar{\rho} \bar{u} u_{t}
\end{gathered}
$$

\section{2) Giles BC}

The Giles boundary condition ${ }^{23}$ resembles the Thompson boundary condition in that they are both based on 1-D characteristics. However, instead of decomposing the equations into normal and tangential components, Giles considered only the normal component and formulated corrections for the effect of the tangential component. Thus, while Thompson's analysis was geared towards only normal and tangential 1-D waves, Giles' analysis allows for waves with other angles of incidence. 
To apply the Giles boundary condition, the interior equations are used at the boundary to compute the time derivatives. The 1-D characteristics are then defined as:

$$
\begin{gathered}
\left(c_{1}\right)_{t}=p_{t}^{\prime}-\bar{\rho} \bar{c} u_{t}^{\prime} \\
\left(c_{2}\right)_{t}=\bar{c}^{2} \rho_{t}^{\prime}-p_{t}^{\prime} \\
\left(c_{3}\right)_{t}=\bar{\rho} \bar{c} v_{t}^{\prime} \\
\left(c_{4}\right)_{t}=p_{t}^{\prime}+\bar{\rho} \bar{c} u_{t}^{\prime}
\end{gathered}
$$

The outgoing characteristics are left unchanged, but the incoming characteristics are modified. At the inflow boundary,

$$
\begin{gathered}
\left(c_{2}\right)_{y}=\bar{c}^{2} \rho_{y}^{\prime}-p_{y}^{\prime} \\
\left(c_{3}\right)_{y}=\bar{\rho} \bar{c} v_{y}^{\prime} \\
\left(c_{4}\right)_{y}=p_{y}^{\prime}+\bar{\rho} \bar{c} u_{y}^{\prime}
\end{gathered}
$$

The time derivatives of the characteristics are computed using:

$$
\begin{gathered}
\left(c_{2}\right)_{t}+\bar{v}\left(c_{2}\right)_{y}=0 \\
\left(c_{3}\right)_{t}+\bar{v}\left(c_{3}\right)_{y}+\frac{1}{2}\left[(\bar{u}+\bar{c})\left(c_{4}\right)_{y}+(\bar{u}-\bar{c})\left(c_{1}\right)_{y}\right]=0 \\
\left(c_{4}\right)_{t}+(\bar{v})\left(c_{4}\right)_{y}-\frac{1}{2}\left[(\bar{u}-\bar{c})\left(c_{3}\right)_{y}\right]=0
\end{gathered}
$$


To account for the incoming vortical gust, the variables are decomposed as shown in Eq. (9). Once the time derivatives of the characteristics are known, Eqs. (10) and (11) are used to determine the time derivatives of the conserved variables.

At the outflow boundary, only one characteristic is corrected. The variables are decomposed as shown in Eq. (8), and the tangential derivatives are taken:

$$
\begin{gathered}
\left(c_{1}\right)_{y}=p_{y}^{\prime}-\bar{\rho} \bar{c} u_{y}^{\prime} \\
\left(c_{3}\right)_{y}=\bar{\rho} \bar{c} v_{y}^{\prime}
\end{gathered}
$$

The incoming characteristic is updated as:

$$
\left(c_{1}\right)_{\imath}+\bar{u}\left(c_{3}\right)_{y}+\bar{v}\left(c_{1}\right)_{y}=0
$$

\section{3) Hagstrom BC}

Again, like the Giles equations, the Hagstrom boundary condition ${ }^{24}$ is formulated in terms of the 1-D normal characteristics:

$$
\begin{gathered}
\left(c_{1}\right)=p^{\prime}-\bar{\rho} \bar{c} u^{\prime} \\
\left(c_{2}\right)=\bar{c}^{2} \rho^{\prime}-p^{\prime} \\
\left(c_{3}\right)=\bar{\rho} \bar{c} v^{\prime}
\end{gathered}
$$




$$
\left(c_{4}\right)=p^{\prime}+\bar{\rho} \bar{c} u^{\prime}
$$

As in the Giles boundary condition, the incoming characteristics are corrected while the outgoing characteristics are left unchanged. However, unlike the Giles boundary condition, the corrections are determined by solving additional equations at the boundary, with the user determining how many equations are needed for accuracy. The effect of these equations is to match to increasing order the short time expansion of the exact boundary solution.

The inflow boundary condition takes the following form:

$$
\begin{gathered}
\left(c_{2}\right)_{t}=0 \\
\left(c_{3}\right)_{t}+\bar{\rho} \bar{c}\left(\bar{u} u_{y}^{\prime}+\bar{v} v_{y}^{\prime}+\frac{1}{\bar{\rho}} p_{y}^{\prime}\right)=0 \\
\left(c_{4}\right)_{t}+\bar{v}\left(c_{4}\right)_{y}+\frac{1}{2} \bar{\rho} \bar{c}(\bar{c}-\bar{u}) v_{y}^{\prime}+\frac{1}{2} \sum_{j=1}^{N}\left(f_{j}+g_{j}\right)=0
\end{gathered}
$$

Here, $f$ and $g$ are the correction equations, which are given by:

$$
\begin{aligned}
& \left(f_{j}\right)_{t}+(\bar{v}+C)\left(f_{j}\right)_{y}+S\left(c_{4}\right)_{y y}=0 \\
& \left(g_{j}\right)_{t}+(\bar{v}-C)\left(g_{j}\right)_{y}+S\left(c_{4}\right)_{y y}=0
\end{aligned}
$$

where 


$$
\begin{gathered}
C=\sqrt{\bar{c}^{2}-\bar{u}^{2}} \cos \left(\frac{j \pi}{2 N+1}\right) \\
S=\frac{\left(\bar{c}^{2}-\bar{u}^{2}\right)}{2 N+1}\left(\sin \left(\frac{j \pi}{2 N+1}\right)\right)^{2}
\end{gathered}
$$

For the inflow condition, the prime terms are defined in Eq. (9).

The ouflow condition is written as:

$$
\left(c_{1}\right)_{t}+\bar{v}\left(c_{1}\right)_{y}+\bar{\rho} \bar{c} \bar{u} v_{y}^{\prime}+\sum_{j=1}^{N}\left(f_{j}+g_{j}\right)=0
$$

Here, the correction equations are given by:

$$
\begin{aligned}
& \left(f_{j}\right)_{t}+(\bar{v}+C)\left(f_{j}\right)_{y}+S\left(p^{\prime}\right)_{y y}=0 \\
& \left(g_{j}\right)_{t}+(\bar{v}-C)\left(g_{j}\right)_{y}+S\left(p^{\prime}\right)_{y y}=0
\end{aligned}
$$

For the outflow equations, the prime terms are defined in Eq. (8).

\section{4) Perfectly Matched Layer}

In the Perfectly Matched Layer (PML) boundary condition, a numerical 'sponge layer' is constructed which surrounds the domain of interest. When a wave propagates into this layer, it is damped with little reflection regardless of the angle of incidence or the wavelength of the incident 
wave.

The PML used here is that of Abarbanel and Gottlieb ${ }^{25}$. In their approach, the Euler equations are linearized about a uniform mean flow in the $\mathrm{x}$-direction. A transformation is applied to the equations, and a PML layer is constructed mathematically. For the cascade problem, the sponge layer is only in the $\mathrm{x}$-direction. The PML equations are given as:

$$
\begin{gathered}
u_{t}^{\prime}+M u_{x}^{\prime}+p_{x}^{\prime}=-\sigma\left(u^{\prime}+M p^{\prime}\right) \\
v_{t}^{\prime}+M v_{x}^{\prime}+p_{y}^{\prime}=-\sigma\left(v^{\prime}+2 Q+\sigma \Psi\right)+\sigma_{x} M P \\
p_{t}^{\prime}+M p_{x}^{\prime}+u_{x}^{\prime}+v_{y}^{\prime}=-\sigma\left(M u^{\prime}+p^{\prime}\right) \\
Q_{t}+\left(1-M^{2}\right) p_{y}^{\prime}=0 \\
P_{t}=\left(1-M^{2}\right)\left(v^{\prime}-\sigma P\right) \\
\Psi_{t}=\left(1-M^{2}\right) Q
\end{gathered}
$$

Here, the $\sigma$ denotes the damping factor, which varies through the layer as:

$$
\sigma(x)=40\left(\frac{x-x_{\text {start }}}{x_{\text {end }}-x_{\text {start }}}\right)^{2}
$$

To implement these equations into the nonlinear code, the equations are transformed into:

$$
\left(u_{t}^{\prime}\right)_{P M L}=-\sigma\left(u^{\prime}+M p^{\prime}\right)
$$




$$
\begin{gathered}
\left(v_{t}^{\prime}\right)_{P M L}=-\sigma\left(v^{\prime}+2 Q+\sigma \Psi\right)+\sigma_{x} M P \\
\left(p_{t}^{\prime}\right)_{P M L}=-\sigma\left(M u^{\prime}+p^{\prime}\right) \\
Q_{t}+\left(1-M^{2}\right) p_{y}^{\prime}=0 \\
P_{t}=\left(1-M^{2}\right)\left(v^{\prime}-\sigma P\right) \\
\Psi_{t}=\left(1-M^{2}\right) Q
\end{gathered}
$$

As before, the prime quantities are determined using Eq. (8) at the outflow, and (9) at the inflow. The Abarbanel and Gottlieb formulation does not include the density equation; to complete the equation set, the flow is assumed to be isentropic:

$$
\bar{c}^{2}\left(\rho_{t}^{\prime}\right)_{P M L}=\left(p_{t}^{\prime}\right)_{P M L}
$$

Once the PML corrections are calculated, they are converted into conserved variables using Eq. (11) and added to the time derivatives computed using the nonlinear Euler equations.

In all calculations, a 20-point PML layer was employed.

\section{Numerical Results}

Two tests were performed for each boundary condition. In both tests, the mean flow was initialized as:

$$
\bar{\rho}=1
$$




$$
\begin{gathered}
\bar{u}=0.5 \\
\bar{v}=0 \\
\bar{p}=\frac{1}{\gamma}
\end{gathered}
$$

The perturbations were initialized as:

$$
\begin{gathered}
\rho_{\text {gust }}(x, y, 0)=0 \\
u_{g u s t}(x, y, 0)=-q(x) \frac{A \beta}{\alpha} \cos (\alpha x+\beta y-\omega t) \\
v_{\text {gust }}(x, y, 0)=-q(x) A \cos (\alpha x+\beta y-\omega t) \\
p_{\text {gust }}(x, y, 0)=0
\end{gathered}
$$

where

$$
q(x)=\left\{\begin{array}{cc}
1 & x<-2 \\
\frac{1}{2}+\frac{1}{2} \cos \left(\frac{\pi}{2}(x+2)\right) & -2<x<0 \\
0 & x>0
\end{array}\right.
$$

In the first test, the cascade is removed from the domain, and the ability of the boundary condition to allow the flow to reach a periodic state is tested. In the second test, the cascade is placed in the flow and the result is compared with the semi-analytic result. 

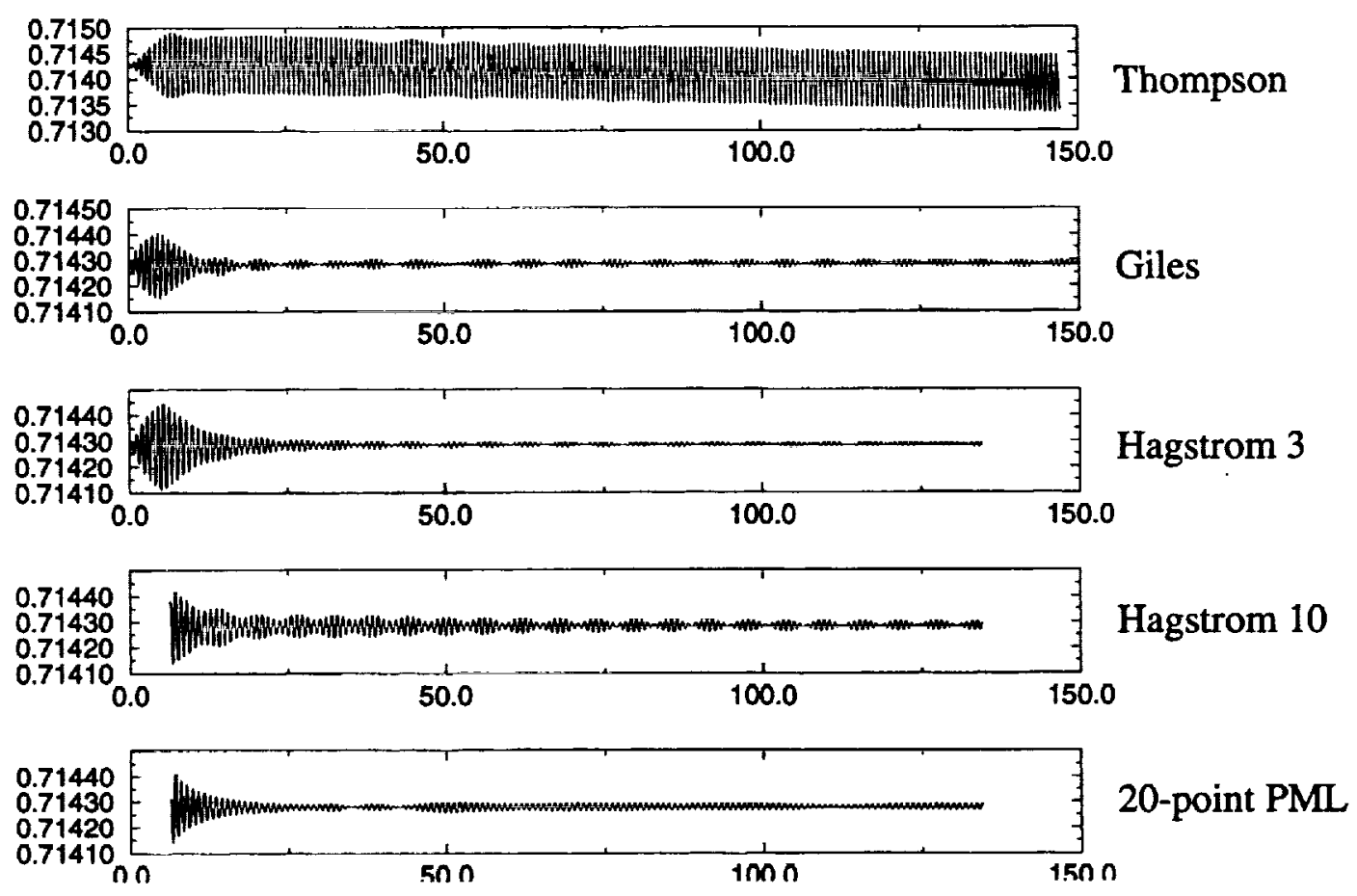

Figure 2: Pressure Time History at Inflow Boundary Point $(-2,0)$
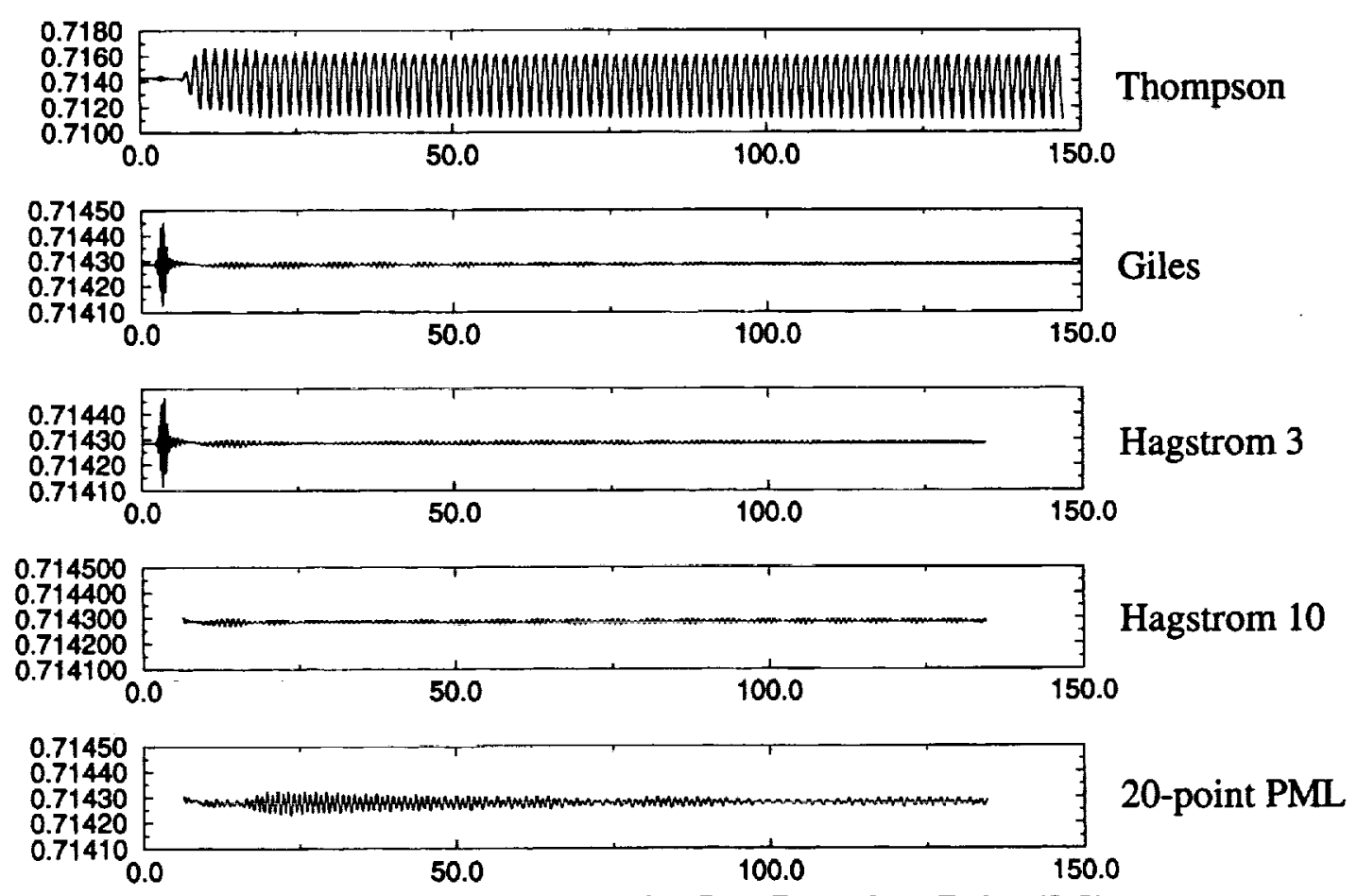

Figure 3: Pressure Time History at Outflow Boundary Point $(3,0)$ 


\section{1) Test Problem 1: No Cascade}

In the first test problem, the domain was initialized with the perturbation given in Eq. (28), and the cascade was removed. This tests the implementation of the upstream disturbance as well as the ability of the outflow boundary condition to allow the vortical gust to convect out without reflection. The grid for all cases had a uniform spacing of $\Delta x=\Delta y=0.02$.

In these problems, the time history of pressure is shown at two points, $(-2,0)$ and $(3,0)$. Figures 2 and 3 show the pressure time history at these two points for the different boundary conditions. From top to bottom, the graphs show the Thompson BC, the Giles BC, the Hagstrom BC using 3 equations, the Hagstrom BC using 10 equations, and the Perfectly Matched Layer (PML) BC. Notice that the scales are all similar except for the Thompson boundary condition, which does not give an adequate solution for this problem. Also, the 10-equation Hagstrom condition does not give a better solution than the 3-equation Hagstrom boundary condition. This is not surprising, as

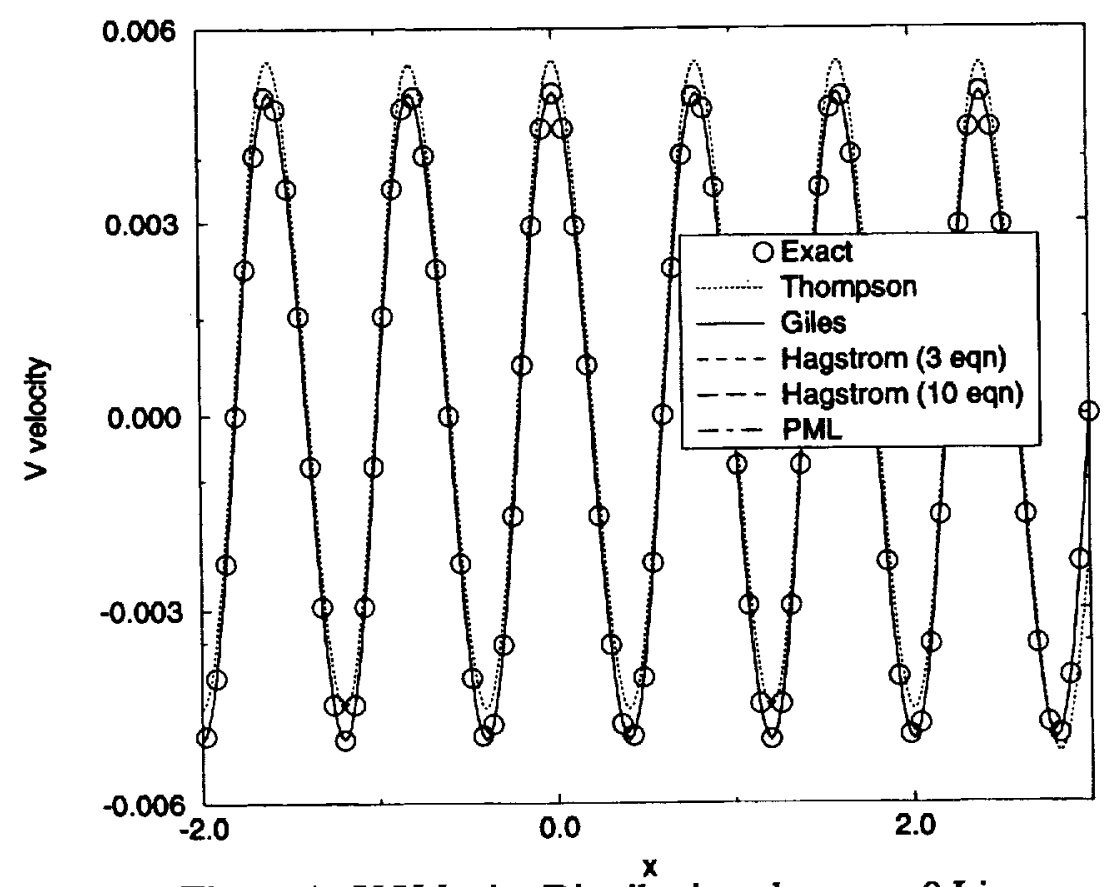

Figure 4: V Velocity Distribution along $y=0$ Line 
the Hagstrom BC is designed to perform well for transients and not for long-term time marching, and, as the number of auxiliary equations is increased, the long-term solution may be less accurate.

Figures 4 and 5 show the $v$ velocity and pressure distributions along the $y=0$ line. The inflow vorticity specification is working well, as shown in Fig. 4. Figure 5 illustrates the pressure error, which is mainly due to the boundary conditions reflecting the outgoing vorticity and the acoustic waves generated by the initial vorticity specification. From Figure 5, the Thompson condition is giving a much worse solution than the other boundary conditions; the other boundary conditions have roughly equivalent levels of error.

\section{2) Test Problem 2: Specified Domain Calculation}

The next calculations were performed on the specified domain, which covered $-2<x<3$. All

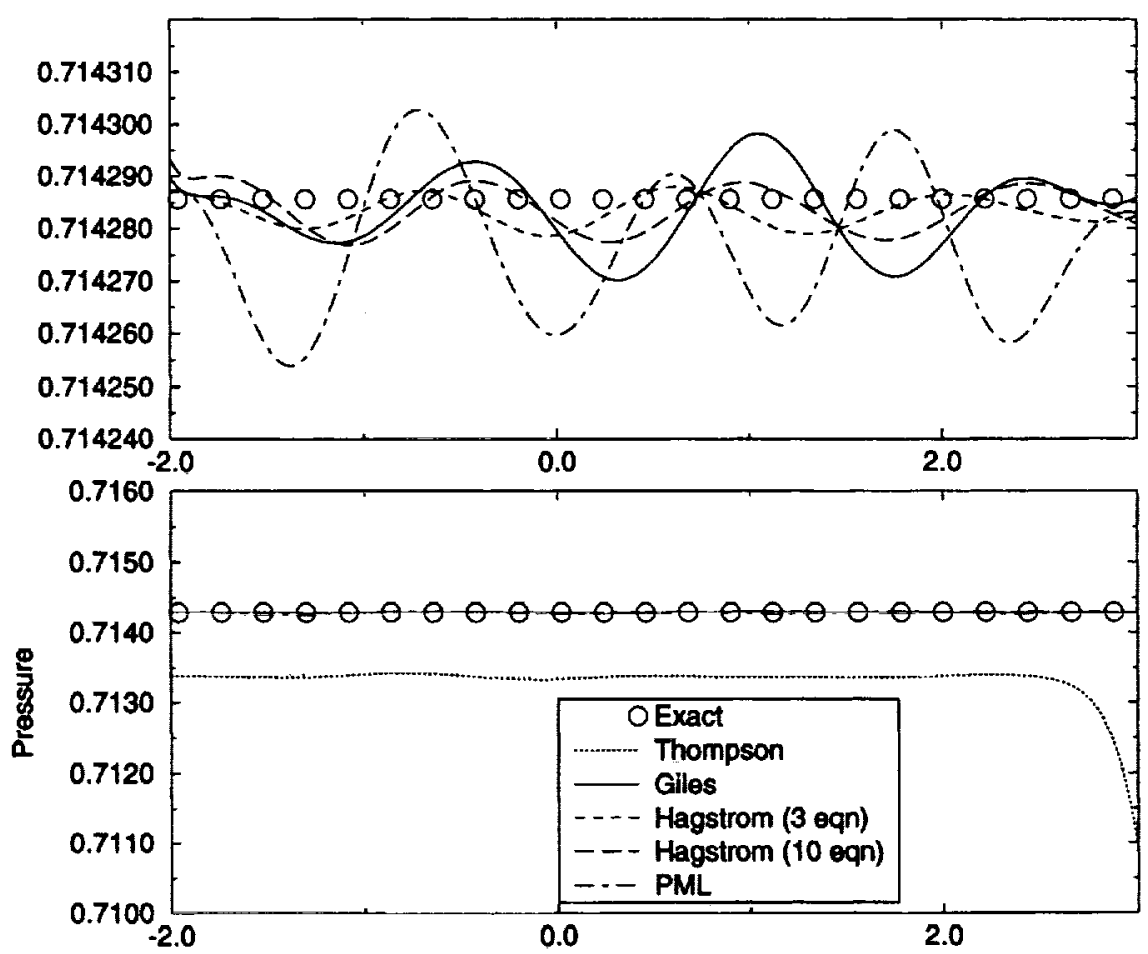

Figure 5: Pressure Distribution along $y=0$ Line 
of the boundary conditions were tested for this configuration.

Figures 6 and 7 show the pressure time history at the inflow and outflow boundary points. Some of the data is fragmentary; this is due to the lead author's inability to type while transferring data.

The Thompson boundary condition proved to be unstable due to reflections from the inflow boundary interacting with the cascade and initiating a feedback loop. Figure 6 illustrates the rapid buildup of pressure in the domain.

The Hagstrom boundary conditions were very slowly unstable for this problem, as Figs. 6 and 7 show. As expected, adding more equations at the boundary improved the transient solution; however, the long-term periodic solution was not improved. Also, as more equations were added. the solutions took longer to converge. Again, it must be noted that the Hagstrom boundary condition was developed for transient problems and not for long-term periodic problems.

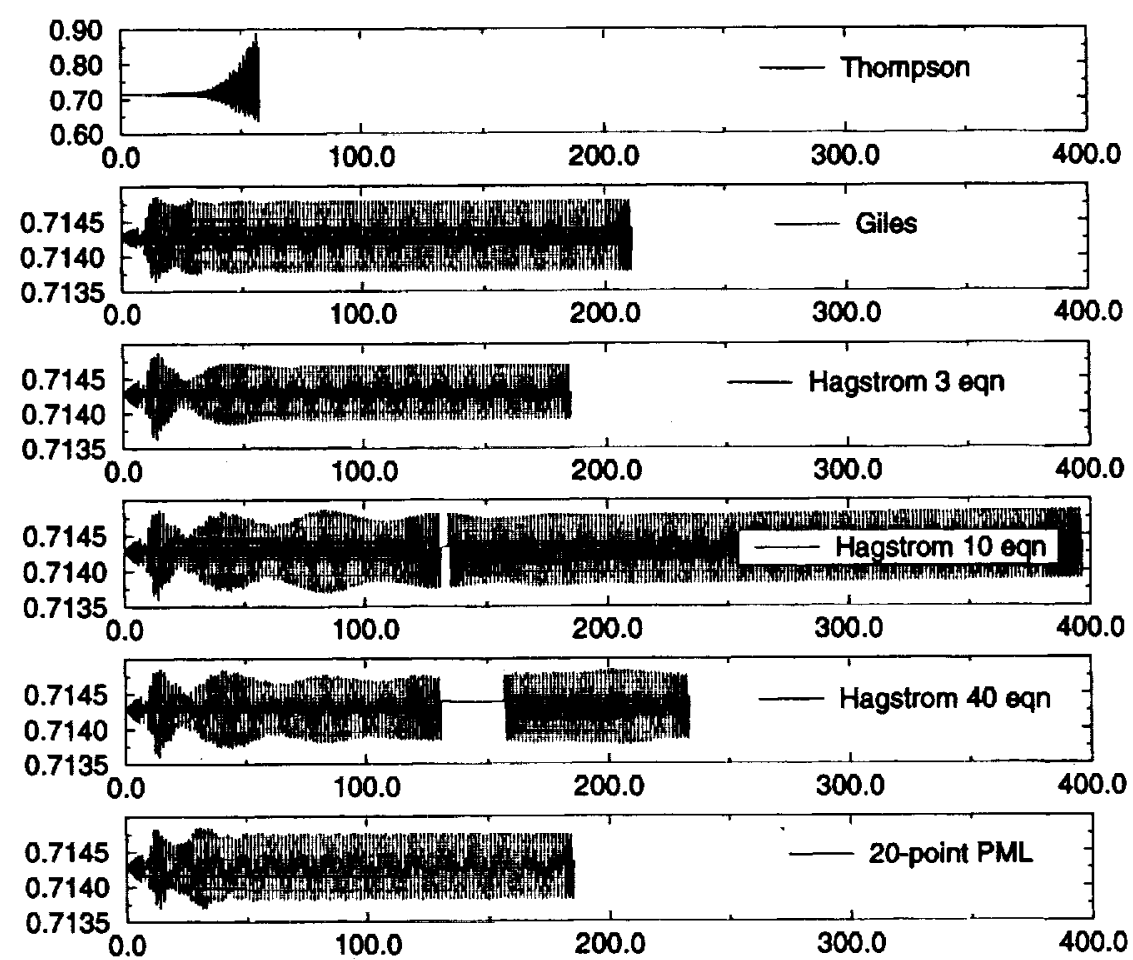

Figure 6: Pressure Time History at Inflow Boundary Point $(-2,0)$ 
Both the Giles and the Perfectly Matched Layer boundary conditions allowed a stable longterm solution to be calculated. The PML condition required extra points in the buffer zone; however, it did improve the solution at the boundary somewhat.

Figures 8 and 9 show the RMS pressure results calculated using these boundary conditions. All solutions were in the same range, with the PML boundary condition performing slightly better than the rest.

Figure 10 shows the pressure difference across the $y=0$ airfoil for the Giles boundary condition; all of the stable boundary conditions allowed identical airfoil results to be obtained. The effect of the numerical singularities at the leading and trailing edge are illustrated. Wall conditions were applied for the upper and lower leading and trailing edge points, with the results being averaged and applied to both points.

It must be noted that these singularities are purely due to the infinitely thin airfoils prescribed
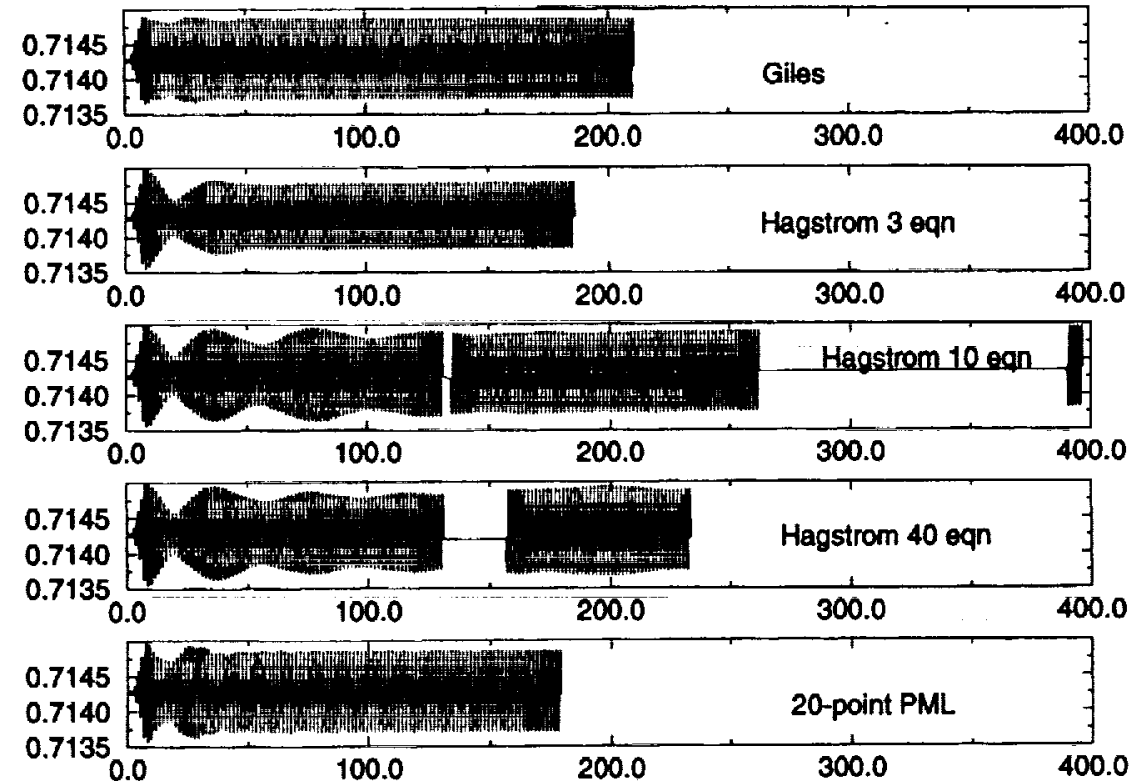

Figure 7: Pressure Time History at Outflow Boundary Point $(3,0)$ 


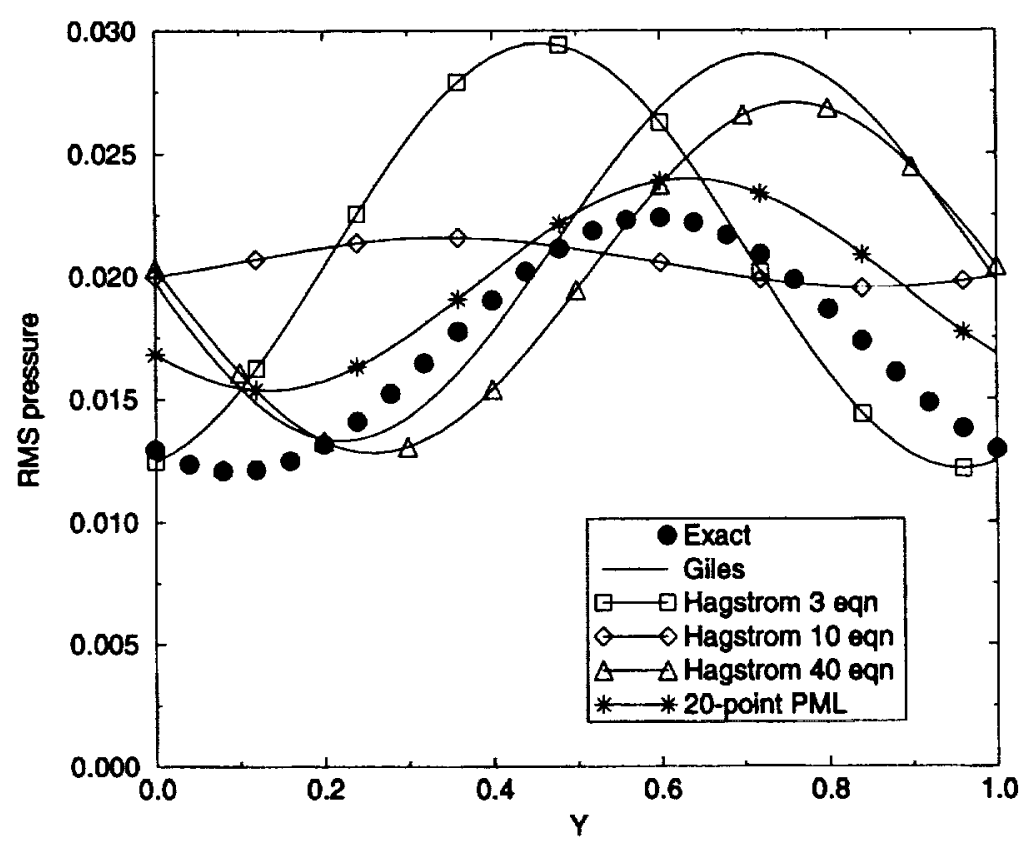

Figure 8: RMS pressure at upstream boundary

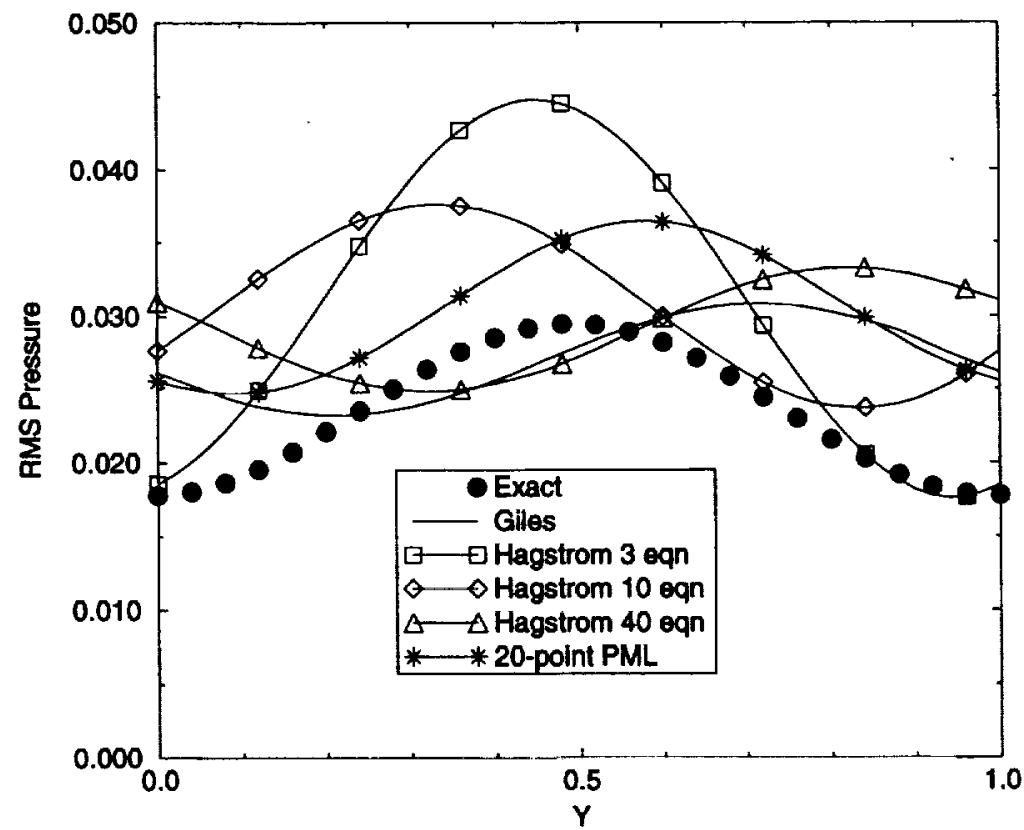

Figure 9: RMS pressure at downstream boundary 
in the problem statement; it is expected that these singularities are the main factor causing the error on the airfoil. Future work will address the effects of real airfoil geometries.

\section{3) Test Problem 3: Long Domain Calculation}

To quantify the relative effect of the numerical singularites and the close boundaries on the computed solution, the same calculation was performed on a long domain $(-8<x<9)$ using the same grid spacing and time step. For these calculations, which required much more CPU time to converge, only the Giles and PML boundary conditions were used. Figure 11 shows that the solution on the sirfoil does not change as compared to the short domain solution.

Figures 12 and 13 show the computed RMS pressure disturbances at the upstream and downstream locations. Using this long domain, both boundary conditions give a solution that is close to the exact solution in phase, with a greater amplitude. It is theorized that the errors in the pressure

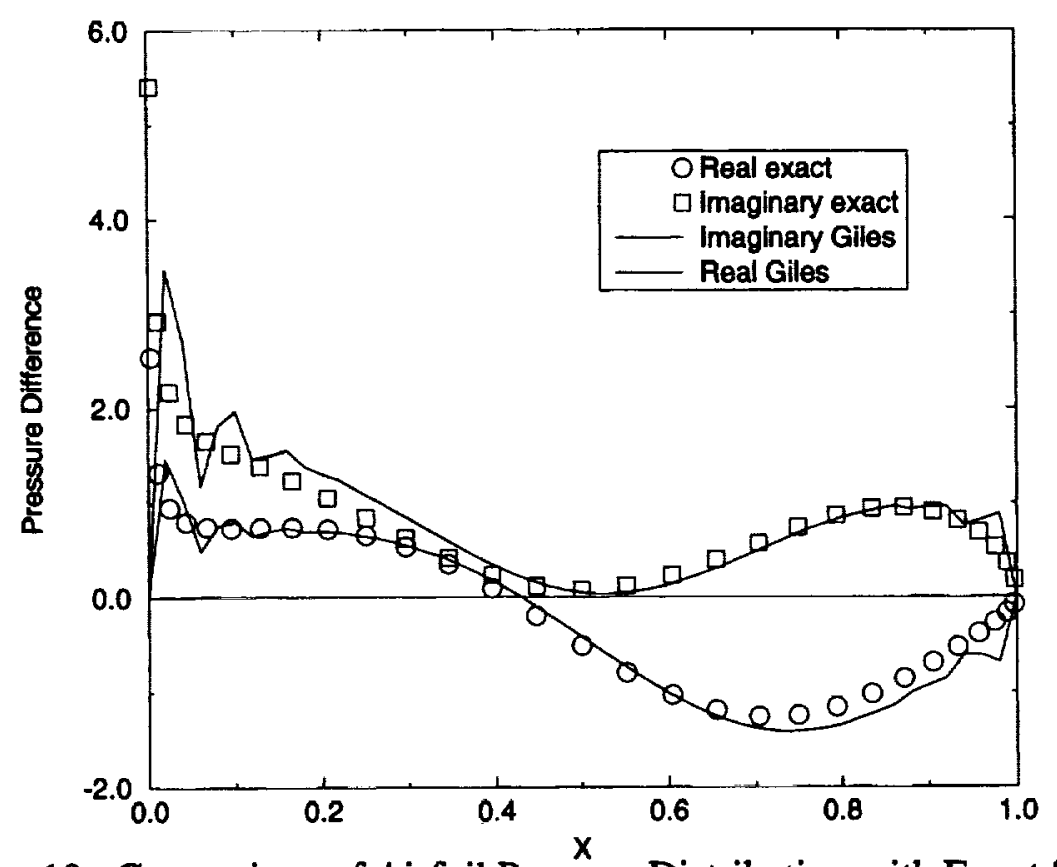

Figure 10: Comparison of Airfoil Pressure Distribution with Exact Solution 
on the airfoil due to the numerical singularities are causing the amplitude error. However, the PML outflow condition is performing better than the Giles outflow condition, as shown in Fig. 13.

Figure 14 shows the effect of the extended domain on the pressure contours using the Giles boundary condition. On the airfoil itself, the contours are nearly identical. In the upstream direction, the contours become different as the inflow boundary is approached, showing that there is some reflection from the inflow boundary condition. In the downstream direction, however, the contours diverge almost immediately after the trailing edge, suggesting that the outflow boundary condition is more reflective than the inflow.

\section{Conclusions}

Several boundary conditions were tested on a CAA Workshop Benchmark Cascade problem. The problem is very difficult due to numerical singularities in the problem specification as well as

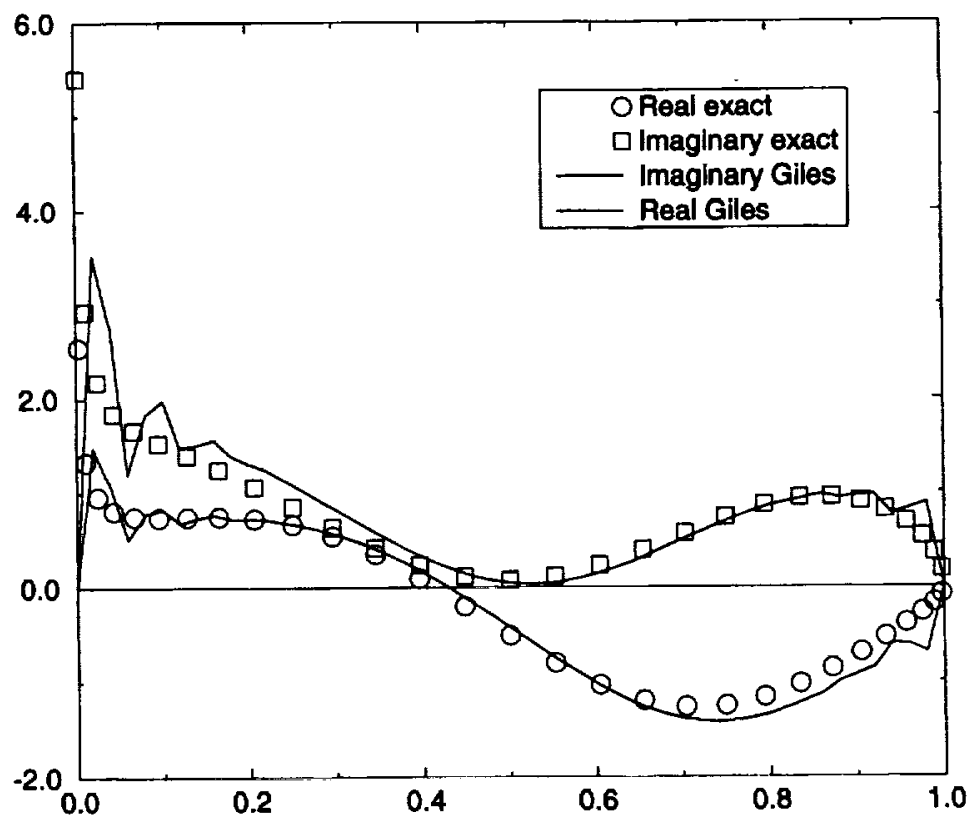

Figure 11: Comparison of Airfoil Pressure Distribution for Long Domain Solution 


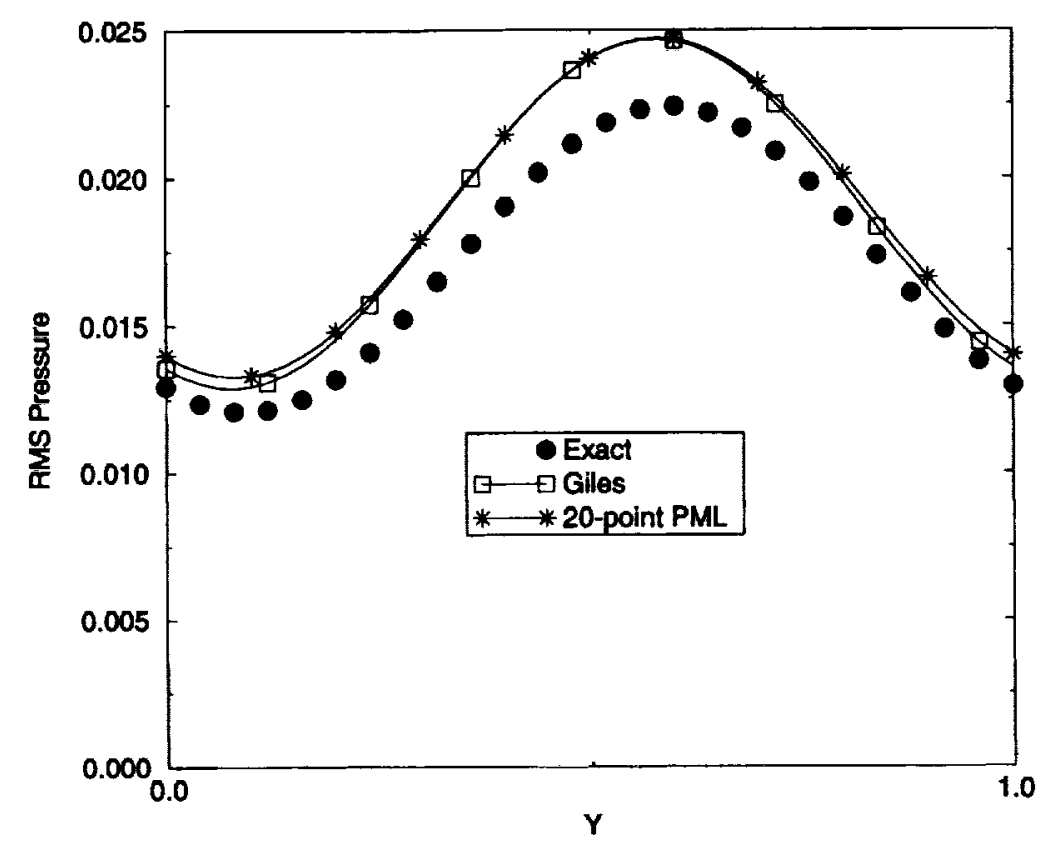

Figure 12: Upstream RMS Pressure Distribution for Long Domain Calculation

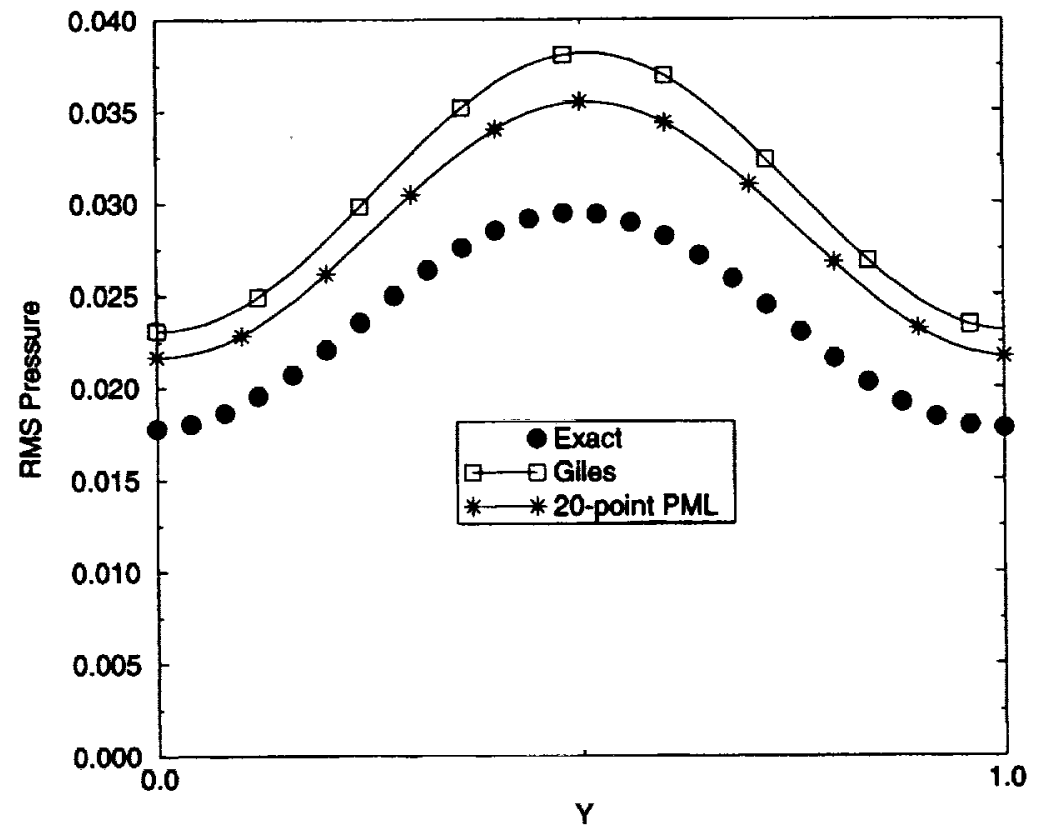

Figure 13: Downstream RMS Pressure Distribution for Long Domain Calculation 
the proximity of the boundaries. Since the problem in periodic in one direction, the ability of the boundary condition to allow acoustic and vortical waves to exit without reflection determines the stability and accuracy of the solution. It was found that the error due to the numerical singularities at the leading and trailing edges of the flat plates kept the solver from obtaining the exact amplitude of the radiated sound; however, the reflected waves at the boundaries due to the boundary conditions kept the solver from obtaining the correct radiation pattern even though the airfoil pressure distribution was nearly identical.

Of the four boundary conditions tested, the Thompson condition was found to have the highest reflection at the boundaries, resulting in code instability. The Giles condition did reasonably well while requiring very little extra computational work. The Hagstrom condition did not perform well for this problem, but it must be noted that it is designed for short-term transient calculations and not long-term periodic problems such as this one. The Abarbanel and Gottlieb PML

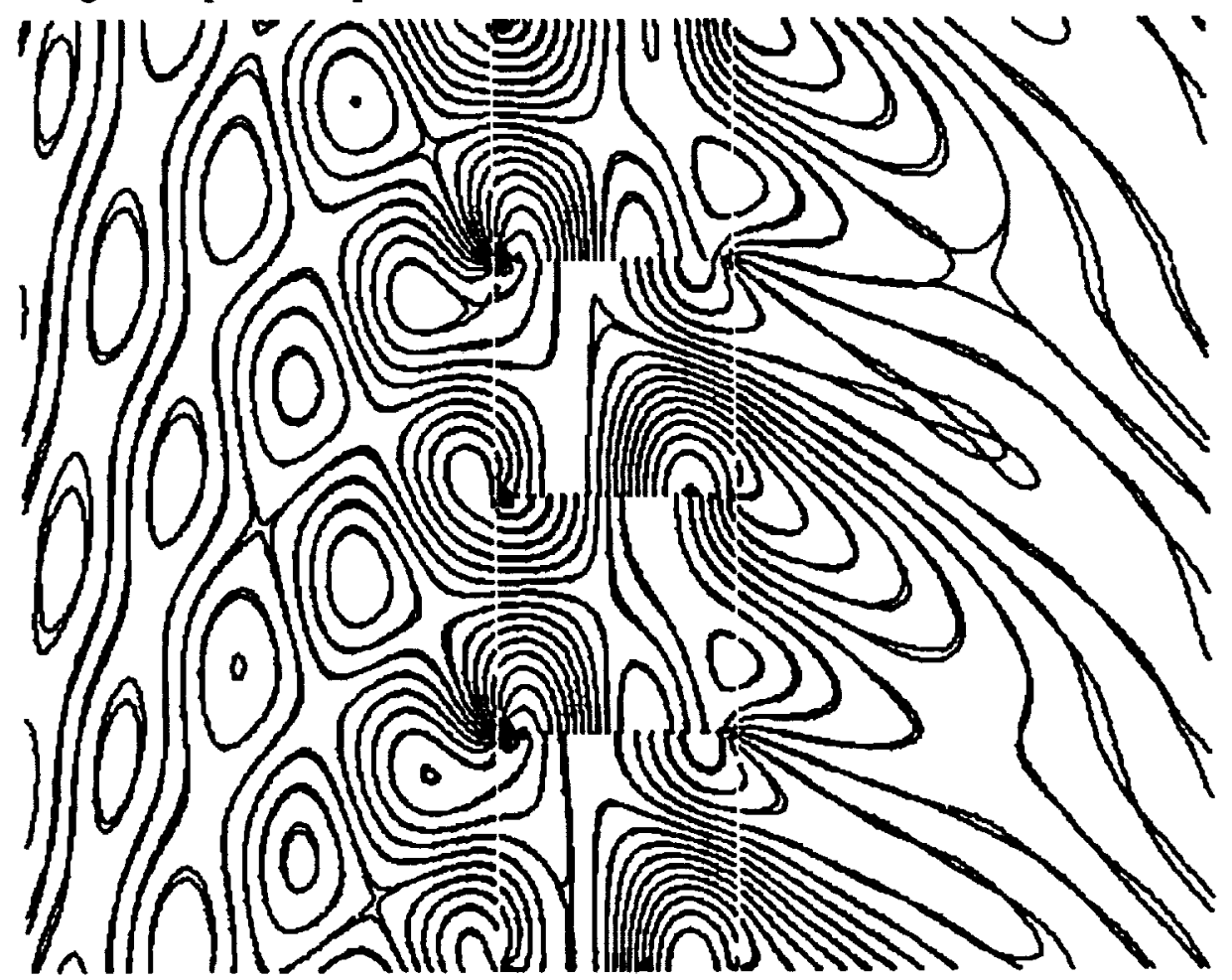

Figure 14: Comparison of Specified-Domain and Long-Domain Instantaneous Pressure Contours with Giles Boundary Conditions 
boundary condition performed the best, but required a 20-point sponge layer at each end. However, the performance of the PML condition could probably be improved with better specification of the damping coefficient distribution in the sponge layer.

Currently, boundary condition specification is one of the main sources of error in time-domain CAA calculations. Work in this area will yield large dividends.

\section{Acknowledgment}

This work was carried out under grant NCC3-531 from the NASA Lewis Research Center. Dr.

L. A. Povinelli was the Technical Monitor.

\section{References}

1) Russo, C. J., 'Changing the Landscape of Civil Aviation', ISABE 97-7002, XIII International Symposium on Air Breathing Engines, Sept. 7-12, Chattanooga, TN, 1997

2) Batterton, P., 'Civil Transport Aircraft Propulsion Challenges and NASA Advanced Subsonic Technology Program', ISABE 97-7044, 1997.

3) Shaw, R. J., 'Progress Toward Meeting the Propulsion Technology Challenges for a 21st Century High Speed Civil Transport, ' ISABE 97-7045, 1997.

4) Groenewig, J. F., Sofrin, T. G., and Rice, E. J., and Gliebe, P. R., 'Aeroacoustics of Flight Vehicles: Theory and Practice', Turbomachinery Noise, edited by Hubbard, NASA PRE-1258, Vol. 1, August, 1991, pp. 151-209.

5) Huff, D. L., 'Fan Noise Prediction: Status and Needs,' NASA/TM-97206533, AIAA-98-0177, 1998.

6) Ventres, C. S., Thebald, M. A. and Mark, W. D., 'Turbofan Noise Generation', NASA CR- 
167952, Vols $1 \& 2,1982$.

7) Meyer, H. D., and Envia, E., 'Aeroacoustic Analysis of Turbofan Noise Generation', NASA CR-4715, March, 1996.

8) Kaji, S. and Okazaki, T., 'Generation of Sound by Rotor-Stator Interaction', J. Sound Vib., Vol. 13, No. 3, pp. 281-307, 1970.

9) Namba, M., 'Three-Dimensional Analysis of Blade Force and Sound Generation for an Annular Cascade in Distorted Flows', J. Sound Vib., Vol. 50, No. 4, 1977, pp. 479-508.

10) Atassi, H., Fang, J. and Hardy, B., 'Sound Radiated From a Loaded Cascade in Nonuniform Transonic Flow', AIAA-96-1756, May, 1996.

11) Lorence, C. B., and Hall, K. C., 'Sensitivity Analysis of the Aeroacoustic Response of Turbomachinery Blade Rows', AIAA 95-0166, 1995

12) Tam. C. K. W., 'Computational Aeroacoustics: Issues and Methods', AIAA 95-0677, 1995.

13) Mankbadi, R. R., 'Computational Aero-Acoustics In Propulsion System', Plenary Lecture, AFOSR Symposium on DNS/LES, Louisiana Tech, August, 1997.

14) Tam, C. K. W., and Hardin, J. C., Second Computational Aeroacoustics Workshop on Benchmark Problems, NASA CP-3352, June 1997.

15) Hu, F. Q. and Manthey, J. L., 'Application of PML Absorbing Boundary Conditions to the Benchmark Problems in Computational Aero-Acoustics', Second Computational Aeroacoustics Workshop on Benchmark Problems, eds. Tam, C. K. W. and Hardin, J., NASA CP-3352, June 1997, pp. 119-152.

16) Lockard, D. A., Morris, P J., 'A Parallel Simulation of Gust/Cascade Interaction Noise', Second Computational Aeroacoustics Workshop on Benchmark Problems, eds. Tam, C. K. W. and Hardin, J., NASA CP-3352, June 1997, pp. 279-288. 
17) Tam, C. K. W., Kurbatskii, K. A., Fang, J., 'Numerical Boundary Conditions for Computational Aeroacoustics Benchmark Problems', Second Computational Aeroacoustics Workshop on Benchmark Problems, eds. Tam, C. K. W. and Hardin, J., NASA CP-3352, June 1997, pp. 191-220.

18) Hall, K. C., 'Exact Solution to Category 3 Problems - Turbomachinery Noise', Second Computational Aeroacoustics Workshop on Benchmark Problems, eds. Tam, C. K. W. and Hardin, J., NASA CP-3352, June 1997, pp. 41-43.

19) Hixon, R., 'A New Class of Compact Schemes', AIAA Paper 98-0367, 1998.

20) Hu, F. Q., Hussaini, M. Y., and Manthey, J. L., 'Low-Dissipation and Low-Dispersion Runge-Kutta Schemes for Computational Acoustics'. J. Comp. Phys., Vol. 124, 1996, pp. $177-191$.

21) Thompson, K. W., 'Time-Dependent Boundary Conditions for Hyperbolic Systems', J. Comp. Physics, Vol. 68, 1987, p. 1-24.

22) Thompson, K. W., 'Time-Dependent Boundary Conditions for Hyperbolic Systems, $\Pi$ ', $J$. Comp. Physics, Vol. 87, 1990, p. 439-461.

23) Giles, M. 'Nonreflecting Boundary Conditions for Euler Equation Calculations', AIAA J., Vol. 28, 1990, p. 2050-2058.

24) Hagstrom, T., 'On high-order radiation boundary conditions', IMA Volume on Computational Wave Propagation', eds. Engquist, B. and Kriegsmann, G., Springer-Verlag, 1996, pp. $1-22$.

25) Abarbanel, S. and Gottlieb, D., 'Perfectly Matched Absorbing Layer for Advective Acoustics', to appear in App. Num. Math. 
Public reporting burden tor this collection of information is estimated to average 1 hour per response, including the time for reviewing instructions, searching existing data sources, gathering and maintaining the data needed, and completing and revlewing the collection of information. Send comments regarding this burden estimate or any other aspect of this collection of information including suggestions for reducing this burden, to Washington Headquarlers Services, Directorate for Intormation Operations and Reports, 1215 Jeflerson Davis Highway, Suite 1204. Artington, VA 22202-4302, and to the Office of Management and Budget, Paperwork Reduction Project (0704-0188), Washington. DC 20503.

\begin{tabular}{|l|l|l|}
\hline 1. AGENCY USE ONLY (Leave blank) & 2. REPORT DATE & 3EPORT TYPE AND DATES COVERED
\end{tabular}

\begin{tabular}{|l|l|l}
\hline & November 1998 & Contractor Report
\end{tabular}

4. TITLE AND SUBTITLE

Evaluation of Boundary Conditions for the Gust-Cascade Problems

6. AUTHOR(S)

R. Hixon, S.-H. Shih and R.R. Mankbadi
5. FUNDING NUMBERS

WU-523-36-13-00

NCC3-531

8. PERFORMING ORGANIZATION REPORT NUMBER

E-11395

Institute for Computational Mechanics in Propulsion

22800 Cedar Point Road

$$
\text { E-11395 }
$$

Cleveland, Ohio 44142

9. SPONSORINGMONITORING AGENCY NAME(S) AND ADDRESS(ES)

National Aeronautics and Space Administration

Lewis Research Center

Cleveland, Ohio 44135-3191

10. SPONSORINGMONITOAING AGENCY REPORT NUMBER

NASA CR-1998-208671

ICOMP-98-06

11. SUPPLEMENTARY NOTES

R. Hixon and S.-H. Shih, Institute for Computational Mechanics in Propulsion, NASA Lewis Research Center;

R.R. Mankbadi, Institute for Computational Mechanics in Propulsion, NASA Lewis Research Center, and Cairo University, Cairo, Egypt. Work funded under Cooperative Agreement NCC3-531.

ICOMP Program Director, Dr. L.A. Povinelli, organization code 5000, (216) 433-5818.

12a. DISTRIBUTIONAVAILABILITY STATEMENT

12b. DISTAIBUTION CODE

Unclassified - Unlimited

Subject Categories: 64, 71, and 34

Distribution: Nonstandard

This publication is available from the NASA Center for AeroSpace Information, (301) 621-0390.

13. ABSTRACT (Maximum 200 words)

Using a high-order accuracy finite-difference time-domain algorithm, the acoustic scattering from a flat-plate cascade is computed. Keeping the grid and time step fixed, the effect of four different boundary conditions on the accuracy and stability of the computed solution is compared.

\section{SUBJECT TERMS}

Boundary conditions; High-order scheme; Compact; Computational aeroacoustics

34

16. PRICE CODE

$\mathrm{AO3}$

17. SECURITY CLASSIFICATION
OF REPORT
Unclassified

18. SECURITY CLASSIFICATION OF THIS PAGE

Unclassified
19. SECURITY CLASSIFICATION OF ABSTRACT

20. LIMITATION OF ABSTRACT

NSN 7540-01-280-5500 
